\title{
Recent developments in electrochemistry at the interface between two immiscible electrolyte solutions for ion sensing
}

\section{Grégoire Herzog}

Laboratoire de Chimie Physique et Microbiologie pour l'Environnement (LCPME), UMR 7564, CNRS Université de Lorraine, 405 rue de Vandoeuvre, Villers-lès-Nancy, F-54600, France.

Email:gregoire.herzog@univ-lorraine.fr; Phone: + 33383685262

This document is a postprint. Final version has been published in The Analyst, 2015, 140, 3888-3896 (https://doi.org/10.1039/C5AN00601E).

\begin{abstract}
Ion transfer at the interface between two immiscible electrolyte solutions allows the non-redox electrochemical detection of ions ranging from protons to macromolecules such as proteins. New electrochemical methods and analytical procedures have been developed in recent years to achieve limits of detection of from $\mu \mathrm{M}$ down to tens of $\mathrm{pM}$ for ion sensing in biomedical diagnostics and in environmental monitoring. This article reviews the developments of the period 2010-2015.
\end{abstract}

\section{Graphical abstract}

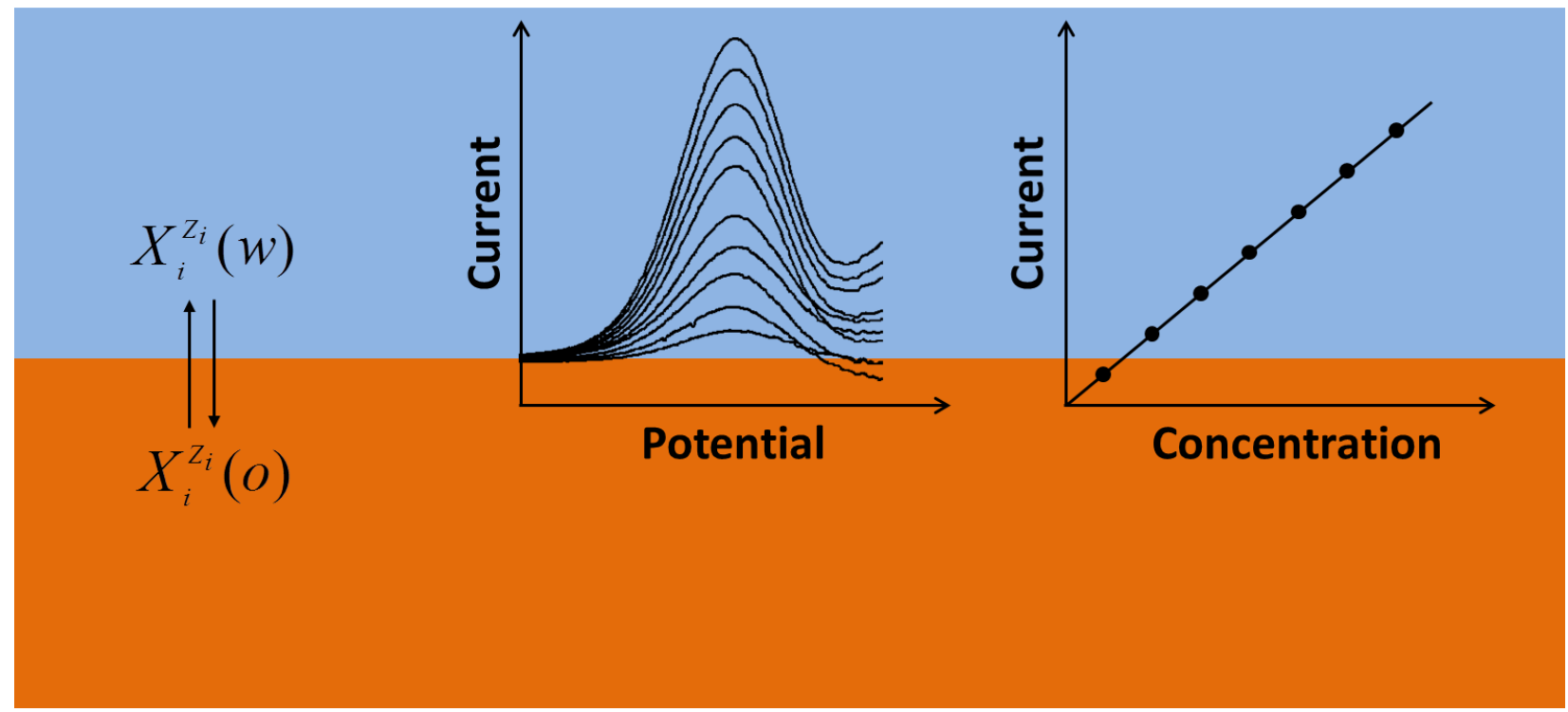

Text for the table of contents : The most recent developments on electrochemical sensing of ions at the liquid-liquid interface are reviewed here. 


\section{Introduction}

The control and understanding of phenomena occurring at the interface between two immiscible electrolyte solutions (ITIES) have triggered the interest of scientists for over a century. Indeed, in 1902, Nernst and Riesenfeld observed visually the transfer of coloured ions from water to phenol upon electrolysis. ${ }^{1}$ From the initial experiments until the mid-1980s, research efforts were focused mainly on the understanding of fundamental phenomena. Since the mid-1990s, the number of research groups interested in electrochemistry at the ITIES has grown and they have contributed to develop applications to answer specific needs. Analytical chemistry is one of the applications of choice when it comes to electrochemistry in general. ${ }^{2}$ Electrochemical sensors are part of a very dynamic field in terms of both academic research ${ }^{3}$ and commercial products (e.g. glucose sensors and ion-selective electrodes). In some electroanalytical applications, the ITIES can replace the working electrode, which is the centre of the transduction mechanism in classical electrochemistry. It offers the opportunity for electrochemical detection of ionic species that are generally not detected by a redox process, with the advantages often associated with electrochemistry (e.g. relatively lowcost analysis and equipment with a short response time). This review will focus on the developments in electroanalytical chemistry at the ITIES reported in the literature during the period 2010-2015. The general principles of electrochemistry at the ITIES will be briefly presented (Part II). Electrochemical events at the ITIES can be associated with direct detection of target analytes (part III). Finally, future perspectives will be given (Part IV).

\section{General principles of electrochemistry at the ITIES}

In traditional electrochemistry, electron transfer reactions take place at the interface between a working electrode and an electrolyte solution. Such reactions require the presence of redox active species in the solution, which can exchange electron with the electrode. The originality of electrochemistry at the ITIES resides in the replacement of the working electrode by an interface between two immiscible liquid phases, allowing the charge transfer study of both redox-active species (by electron transfer) and ionic species (by ion transfer). Electron transfer reactions at the ITIES require the redox reaction between an oxidised form of a redox couple in one phase and the reduced species of a second redox couple in the other phase. Electron transfer has scarcely been used for sensing and it won't be reviewed here. More interesting from the analytical point of view, the ITIES allows the electrochemical study of ionic species that are not necessarily detected by a redox process. The electrochemical signal recorded is generated by the transfer of ionic species through the interface. In the case of ionic species, their transfer can be induced by the application of a Galvani potential difference, $\Delta_{o}^{w} \varphi$, across the interface. Equation (1) presents a form of the Nernst equation that applies to the ITIES: 


$$
\Delta_{o}^{w} \varphi=\Delta_{o}^{w} \varphi_{i}^{0}+\frac{R T}{z_{i} F} \ln \frac{a_{i}(o)}{a_{i}(w)}
$$

$z_{i}$ is the charge of $i$ and $a_{i}$ stands for the activities in each phase. $\Delta_{o}^{w} \varphi_{i}^{0}$ is the standard transfer potential of the ion $i$, which is related to the standard Gibbs energy of ion transfer $\Delta G_{t r, i}^{0, w \rightarrow o}$ as shown by Equation (2).

$$
\Delta_{o}^{w} \varphi_{i}^{0}=\frac{\Delta G_{t r, i}^{0, w \rightarrow o}}{z_{i} F}
$$

Hydrophilic ions will have a positive $\Delta G_{t r, i}^{0, w \rightarrow o}$ value (i.e. they will transfer at a largely positive $\Delta_{o}^{w} \varphi$ values), whereas hydrophobic ions will present negative $\Delta G_{t r, i}^{0, w \rightarrow o}$ value (i.e. they will transfer at a largely negative $\Delta_{o}^{w} \varphi$ values). Addition of an ionophore to the electrochemical cell can facilitate the ion transfer, by lowering the Gibbs energy of transfer required. The potential difference at which a transfer is observed gives an indication of the nature of the ionic species transferring, whereas the charge recorded is proportional to the amount of ionic species transferred. As a convention, cations transferring from the aqueous phase to the organic phase and anions transferring from the organic phase to the aqueous phase give rise to a positive current. Inversely, anions transferring from the aqueous phase to the organic and cations transferring from the organic phase to the aqueous phase are responsible for negative currents. Typically, the organic solvent used is 1,2-dichloroethane, 1,6dichlorohexane or nitrobenzene in which highly hydrophobic electrolyte salts are dissolved. Recent studies have explored new organic solvents (trifluorotoluene ${ }^{4}$ and 5 -nonanone ${ }^{5}$ ) or mixture of solvents $^{6}$ for electrochemistry at the ITIES. Hydrophobic room temperature ionic liquids can also be used as a replacement to the organic phase. ${ }^{7}$ The aqueous phases are usually prepared from common electrolyte salts ( $\left.\mathrm{LiCl}, \mathrm{KCl}, \mathrm{NaCl}, \mathrm{MgCl}_{2}, \mathrm{Li}_{2} \mathrm{SO}_{4} \ldots\right)$. The full range of techniques available at solid electrodes can be used at the ITIES, making possible the electrochemical studies of ions that cannot be detected by redox processes. For further details on electrochemistry at the ITIES, readers are invited to consult text books, ${ }^{8,9}$ detailed reviews and monographs ${ }^{10-25}$ already published on the subject. For example, the principles of electrochemistry at the ITIES were thoroughly described $^{10,12,15,16,19,25}$ or with an emphasis on interface modification, ${ }^{13}$ electrocatalysis $^{17}$ or electroanalysis. ${ }^{11,14,18,20-24}$

\section{Sensing}

Ion sensing is a major challenge in both environmental monitoring and clinical diagnosis. A wide range of ions have been detected by ion transfer controlled by electrochemistry. However, simple electrochemical cells with a macroscopic interface do not favour a sensitive detection method. A number of strategies (i.e. microscopic ITIES and hydrodynamic conditions) are employed to improve 
mass transport and, hence, the sensitivity. This improvement is often accompanied with an optimisation of the electrochemical method employed.

Interface types. Different methods exist to build a liquid-liquid interface for electrochemical measurements (Figure 1). Classical macroscopic glass cells generally offer an interface with a surface area in the $\mathrm{cm}^{2}$ range (Figure $1 \mathrm{~A}$ ) and have been used to investigate electroanalytical behaviour of myoglobin ${ }^{26}$ and poly-Lysine dendrigrafts. ${ }^{27}$ Although widely used for other applications, their use for analytical purposes is rather limited due to linear diffusion of species and unstable mechanical properties. The other types of interfaces were developed to overcome the limitations of the classical approach. The mechanical stability can be improved by the use of a porous membrane that supports the ITIES (Figure 1B). Creatinine, ${ }^{28}$ heparin, ${ }^{29}$ albumin $^{30}$ and inorganic cations ${ }^{31-34}$ and anions ${ }^{35}$ have $^{2}$ been detected at such membrane-supported ITIES. Bakker and colleagues used a tubular liquid-liquid cell for ion transfer coulometry. ${ }^{31}$ The cell was made of a silver - silver chloride wire inserted in a porous polypropylene tube impregnated with the organic phase. A thin aqueous layer (approximately $50 \mu \mathrm{m}$ thick) is formed between the polypropylene tube and the wire. Ions are transferred from the aqueous layer to the organic phase supported by the porous polypropylene tube (Figure 2A). The thin layer of aqueous solution and its known volume allows total transfer of the ions monitored by coulometry, resulting in a calibration-free determination of ion concentration. A liquid-liquid interface can also be formed using a solid electrode impregnated with a thin organic layer and then immersed in an aqueous electrolyte solution (Figure 1C). This method offers the advantage of using low volumes of organic phase. The organic solution contains a redox species, which can exchange electron with the electrode. Ions then transfer from the aqueous phase to the organic phase to maintain electroneutrality. The transfer potential depends on the hydrophobicity / hydrophilicity of the ions constituting the aqueous electrolyte. This approach has been used for the detection of inorganic cations ${ }^{36-41}$ and perfluoroalakanesulfonates. ${ }^{42}$ Nevertheless, the sensitivity of macroscopic ITIES can be restricted by a linear diffusion of species. Amemiya and colleagues circumvented this drawback by forming the organic gel containing a conducting polymer on a rotating disc electrode made of either gold or carbon. ${ }^{42,39,41}$ The improved mass transport due to the convection resulted in limits of detection in the sub-nanomolar concentration range. Mass transport was also be improved by the miniaturisation of ITIES and resulted in better sensitivities and limits of detection. Different fabrication strategies to prepare these $\mu$ ITIES exist and have been reviewed elsewhere. ${ }^{20,22}$ ITIES of microscopic dimensions are now routinely used under the form of a single $\mu$ ITIES ${ }^{43-48,37,49-51}$ (Figure 1D) or of an array of $\mu$ ITIES ${ }^{52-70}$ (Figure 1E) allowing to reach limits of detection in the range of tens of $\mathrm{nM}$ with an analysis time of a couple of minutes. Diffusion of ionic species at $\mu$ ITIES has shown an asymmetric profile. ${ }^{18}$ In the case where the micropipette or the pores are filled with the organic phase (i.e. analogous to inlaid microelectrodes), radial diffusion of species is observed and a sigmoidal signal is recorded for the ion transfer. If the ionic species remain confined within the 
capillary or within the pore of the membrane, linear diffusion will predominate and a peak shaped voltammogram will result. The electrochemical behaviour of reversible ion transfer has been theoretically modelled for a variety of electrochemical techniques (cyclic, linear sweep, square wave, normal pulse and differential pulse voltammetries). ${ }^{71-73}$ The influence of adsorption of the ionic species on the pore walls after the transfer was also investigated by finite element simulations. ${ }^{74}$ The critical dimension of the ITIES was further reduced down to the nanometer scale using single nanoITIES ${ }^{75}$ or nanoITIES arrays fabricated by e-beam lithography ${ }^{76}$ or focused ion beam. ${ }^{77}$ NanoITIES arrays were characterised by cyclic voltammetry ${ }^{76-79}$ and chronoamperometry ${ }^{80}$ of model ions such as tetraethylammonium or tetrapropylammonium. Scanlon and Arrigan demonstrated that nanoITIES arrays were 50 times more sensitive than $\mu$ ITIES arrays and 1000 times more sensitive than a single macrolTIES. ${ }^{79}$ However, the sensitivity obtained at such nanolTIES was only half of the theoretical one. The authors attributed this discrepancy to the non-equivalence of the nanolTIES in the array and to an overlap of the diffusion zones, ${ }^{78}$ a claim later supported by finite element simulations. ${ }^{81}$ Detection of propranolol by cyclic voltammetry at an array of nanoITIES resulted in a limit of detection of $0.8 \mu \mathrm{M}$, which is $5-10$ times lower than the limit of detection achieved at larger interfaces. ${ }^{81}$

All the examples above described the variety of the physical nature (membrane-supported ITIES, thin organic layer and miniaturised ITIES) of interfaces that was used to improve the analytical performances. The type of interface can also be changed by modifying the nature of the hydrophobic phase. The properties of hydrophobic ionic liquids of low volatility and of high conductivity have established them as a good alternative for organic solvent in electroanalytical applications ${ }^{82}$. Ding and colleagues investigated the transfer potential of inorganic cations $\left(\mathrm{Sr}^{2+},{ }^{48} \mathrm{Rb}^{+},{ }^{49} \mathrm{Cs}^{+50}\right.$ and uranyl species ${ }^{83}$ ) assisted by octyl(pheny)- $N, N$-diisobutylcarbamoylmethylphosphine oxide dissolved in a hydrophobic room-temperature ionic liquid. Their studies have estimated the stoichiometry of complexes formed between the metal ions and the ligand and their complexation constant, $\beta$. The stoichiometry of the complexes determined by electrochemistry was correlated with the one obtained by mass spectrometry, ${ }^{49,50}$ establishing electrochemistry at the liquid-liquid interface as a simple analytical method for the studies of metal on-ligand complexation.

Detection methods. Stripping voltammetry at the ITIES has been widely used since the early $1990 \mathrm{~s},{ }^{22}$ and it remains used as it is one of the most sensitive techniques for ion sensing. Since 2010, it has been used for the detection of proteins, ${ }^{54,55,58,59}$ ionic drug molecules, ${ }^{61,63,64}$ pollutants, ${ }^{44,45,27,42}$ and inorganic species (both cations $\mathrm{s}^{47,39,41}$ and anions ${ }^{67-69}$ ). Stripping voltammetric studies improved the limits of detection and the sensitivities by at least one order of magnitude compared to cyclic voltammetry. Computational simulations have shown that the asymmetric diffusion behaviour, discussed in the following section, is beneficial for the analysis by stripping voltammetry. ${ }^{84,85}$ Indeed, the radial diffusion in the aqueous phase ensures a high mass transport rate for the preconcentration 
step, whereas the linear diffusion in the organic phase limits the diffusion of the target analyte away from the interface. The preconcentration can be further improved by using a poly-(vinyl chloride) gel as the organic phase, which restraints diffusion of species. More recently, Arrigan's group harnessed the specificity of protein electrochemistry at the ITIES (described in a previous section) to devise an adsorptive stripping voltammetry protocol. The target protein is accumulated at the ITIES via potential-dependent adsorption. ${ }^{55}$ They demonstrated that several layers of proteins accumulated at the interface and that the saturation of the analytical signal was the result of protein reorganisation at the interface rather than diffusion-limited. First demonstrated with lysozyme, this approach was then extended to insulin ${ }^{58}$ and haemoglobin..$^{59}$

Stripping voltammetry determination of ions has used the current as the analytical signal, whereas Bond and colleagues have developed voltammetric ion-selective electrodes for the detection $\mathrm{Na}^{+}, \mathrm{K}^{+}$ and $\mathrm{Ca}^{2+}, 36,40$ based on ITIES formed at electrodes modified with thin-organic films (Figure 1C). The transfer peak potential varied linearly with the logarithm of the target ion activity and was used as the analytical signal for the detection of $\mathrm{Na}^{+}, \mathrm{K}^{+}$and $\mathrm{Ca}^{2+}$ in a variety of real samples.

In most analytical applications, calibration of the sensors remain a critical issue. Bakker's group has developed a coulometric method using the thin layer cell described in the previous section and in Figure $2 . .^{31,32,86}$ This experimental set-up could be used for the calibration-free determination of ion concentration. A series of potentiostatic and galvanostatic pulses was used to compensate the contribution of interfering ions to the coulometric response. First, a potential equal to the open circuit potential was applied to verify the absence of ion transfer (i.e. current is 'zero'). The transfer potential was then applied and the current was measured as a function of time. During this chronoamperometric step, both the target analyte and interfering ions are transferred, and hence both contributing to the current response. After a resting period with zero current applied, the second potentiostatic step was applied, during which only the interfering ions transferred. Indeed, since a thin layer cell was used, the aqueous phase is completely depleted from target ions and only interfering ions, which are at a much higher concentration, remain. The current of the second potentiostatic pulse is subtracted from the first one to determine the contribution of the sole target ions. This method was successfully used for the selective detection of $\mathrm{Ca}^{2+}(10 \mu \mathrm{M}), \mathrm{K}^{+}(0.1 \mu \mathrm{M})$ and $\mathrm{NO}_{3}^{-}(1.1 \mu \mathrm{M})$. The same type of ion selective membrane was then adapted for the indirect determination of heparin in undiluted blood samples, using a thin layer coulometric cell. ${ }^{29}$ Heparin is an anticoagulant used during surgical procedures, known to interact with protamine. Protamine is transferred across the interface and the charge transfer recorded increased linearly with the concentration in both laboratory and undiluted blood samples. In the presence of heparin, protamine was bound to it and thus, was not available for transfer anymore, leading to a drop in the charge transferred. Quantitation of the unbound protamine remaining has led to the heparin concentration in the analysed sample. 
Target analytes. The sensing of molecules of biological interest (small organic molecules, ${ }^{52,53,28,87}$ carbohydrates, $^{88,29}$ and proteins ${ }^{26,54-56,30,57-60}$ ), synthetic organic molecules (drug molecules, ${ }^{61,43,62-}$ $64,81,89$ pollutants ${ }^{44,45,27,42}$ ) and inorganic species (both cations ${ }^{36,46,31,32,47,48,33,37,38,49,65,34,39,40,51,50,66,41}$ and anions ${ }^{67,35,68}$ ) has been extensively studied in the 2010-2015 period covered in this mini-review (see Table 1 of the Supplementary Information section for more details). Although the detection of some analytes was already targeted before 2010 (e.g. dopamine, ${ }^{14,20}$ propranolol, ${ }^{90}$ and heparin ${ }^{91}$ ), other types of ionic species have recently been detected at the ITIES. Proteins (albumin, ${ }^{30}$ amylin, ${ }^{57}$ haemoglobin, ${ }^{59}$ insulin,, ${ }^{58}$ lysozyme, ${ }^{55}$ myoglobin $^{56}$ ) and peptides issued from the enzymatic proteolysis ${ }^{54}$ have been detected by ion transfer voltammetry. This analytical development resulted from fundamental studies on the electrochemical behaviour of proteins. ${ }^{92}$ The detection of proteins at the ITIES is generally based on two different types of facilitated ion transfers (Figure 3A-B). In the first case, the protein is dissolved in the aqueous phase. Upon the application of an interfacial potential, proteins adsorbed at the interface and facilitates the transfer of anions of the supporting electrolyte salt of the organic phase (as schematised on Figure $3 \mathrm{~A}$ ). The current arising from this ion transfer is used as the analytical signal for protein detection. (Figure 3C). Earlier works have shown that proteins can only be detected at the ITIES when they were positively charged (i.e. $\mathrm{pH}<\mathrm{pl}$ ) as their detection resulted from an interaction with the anion of the organic electrolyte. ${ }^{92}$ This approach was used successfully for the detection of myoglobin ${ }^{56}$ by cyclic voltammetry and for the detection of lysozyme, ${ }^{55}$ insulin $^{58}$ haemoglobin ${ }^{59}$ using adsorptive stripping voltammetry with detection limits in the range of tens of nanomolar. The sensitivity of the protein detection depends on its charge and on the possibility of the organic anion to interact with hydrophobic pockets within the protein structure. Electroanalytical studies have shown that the technique is more sensitive for proteins than for dendrimers deprived of these hydrophobic patches. ${ }^{27}$ In the second case, proteins are present in the aqueous phase and anionic surfactants are dissolved in the organic phase (Figure 3B). Anionic surfactants allow the transfer of the protein across the interface, giving rise to a current, which can be used as the analytical signal (Figure 3D). ${ }^{26,60}$ Osakai et al. have investigated the use of a variety of surfactants for the transfer of cytochrome $c$, ribonuclease A, lysozyme, albumin, myoglobin and $\alpha$ lactalbumine. ${ }^{26}$ They suggested that the anionic surfactants interacted with the positively charged amino acids (lysine, arginine and histidine) of the proteins. Cyclic voltammograms for cytochrome $c$, haemoglobin and myoglobin in the absence (Figure $3 \mathrm{C}$ ) and in the presence (Figure 3D) of anionic surfactant in the organic phase showed that both approaches allowed the detection of protein. However, the use of anionic surfactant as an ionophore assisting protein transfer through the interface, improved the peak current by a factor 6 in comparison to the signal obtained in the absence of surfactants. ${ }^{60}$ The majority of proteins investigated at the ITIES did not transferred across the interface unless a surfactant was used to facilitate the transfer. The mechanism for the detection of amylin at the ITIES was different as it transferred unassisted across the interface. The polypeptide could then be detected at physiological $\mathrm{pH}$ from a protein mixture. ${ }^{57}$ Small organic molecules such as 
ionic drugs (propranolol, ${ }^{61,43,63,81}$ daunorubicin ${ }^{62}$ and ractopamine $^{64}$ ) were also detected by ion stripping voltammetry at micro-interface arrays. Limits of detection of $50 \mathrm{nM}$ were reached for propranolol, ${ }^{63} 800 \mathrm{nM}$ for daunorubicin ${ }^{62}$ and $100 \mathrm{nM}$ for ractopamine. ${ }^{64}$ These concentrations are suitable for detection in real samples, however the interactions between drugs and plasma proteins required the deproteinisation of the serum before detection. ${ }^{61,62,64} \mathrm{~A}$ single $\mu$ ITIES was also used to investigate the chiral interactions of (S)- and (R)-propranolol with a serum protein: $\alpha_{1}$-glycoprotein. ${ }^{43}$ Lopes and Kataky have demonstrated that the transfer signal for propranolol decreases in the presence of the protein as a consequence of the protein-drug complexation and that the interaction of (S)-propranolol with $\alpha_{1}$-glycoprotein is greater than in the case of (R)-propranolol. Amemiya's group has focused its attention on the detection of perfluoroalkanesulfonates and perfluoroalkanecarboxylates by ion transfer voltammetry. ${ }^{42}$ A limit of detection of $50 \mathrm{pM}$ was reached, which is below the maximum authorised concentration set in the US. The detection of perfluoroalkanesulfonates ion transfer voltammetry is superior to its detection by electroanalysis at solid electrodes as the oxidation of perfluoroalkanesulfonates is more difficult than their nonfluorinated analogues. On the contrary, perfluoroalkanesulfonates are more hydrophobic and are hence more easily detected at the liquid-liquid interface.

The variety of interface types and of detection methods has led to the improvement of sensitivities and limits of detection for an increasing number of target analytes. However, most of the studies described above were done in clean laboratory solutions. The number of target analytes detected in real samples remained limited to a few biological samples (urine ${ }^{28,30}$ whole blood, ${ }^{29,40}$ and plasma ${ }^{40}$ ) fresh water, ${ }^{40,35,68}$ and drinks. ${ }^{40}$ Target analytes such as heparin, $\mathrm{Na}^{+}, \mathrm{K}^{+}$and $\mathrm{Ca}^{2+}, \mathrm{NO}_{3}{ }^{-}$and $\mathrm{ClO}_{4}{ }^{-}$were detected in those complexes matrices despite the presence of possible interferents.

\section{New horizons}

Recent developments in the field of electrochemistry at the ITIES have emerged over the past few years. Although they have not necessarily resulted in analytical applications yet, they offer promising perspectives for the future. They include the electrochemistry of two interfaces at supported liquid membranes, the coupling of ITIES with other analytical techniques and the modification of the ITIES.

Electrochemistry at supported liquid membranes systems. In such experiments, an organic phase is supported by a porous membrane and is sandwiched between two aqueous electrolyte solutions (Figure 4A). This method has found analytical applications for extraction and sample preparation. ${ }^{93,94}$ When combined with electrochemistry at the ITIES, a hydrophobic electrolyte is dissolved in the organic phase, leading to two polarisable liquid-liquid interfaces. A potential difference is applied across the supported liquid membrane to favour the transfer of ionic species from one aqueous solution to the other across the supported organic electrolyte solution..$^{95}$ Dryfe and co-workers investigated the ion transfer mechanism at such supported liquid membranes systems. ${ }^{96,97}$ Their 
experimental setup consisted of two aqueous phases separated by a supported liquid membrane. In both aqueous phases, the same ion was dissolved. ${ }^{97}$ As a consequence, the potential window was the double of the one observed for a single ITIES setup, resulting in the appearance of two couples of ion transfer peaks, each couple corresponding to the reversible transfer from one of the aqueous phases to the membrane (Figure 4B). Transfer potentials of these ions are dependent on their hydrophilicity. As seen on Figure 4B, the most hydrophilic ions require more energy and the couples of transfer peaks are more separated. As the hydrophobicity increases, the separation between the couple of transfer peaks decreases, although their transfer potentials remain distributed symmetrically about the zero potential difference. The understanding of the double transfer of ions across the supported liquid membrane has an impact on the development of applications in the field of ion separation, purification and detection.

Coupling with other analytical techniques. Since the origin of electrochemical studies at the ITIES, there has been an interest to correlate electrochemical information with other analytical techniques (e.g. spectroscopy techniques being among the most popular ones). ${ }^{12,98}$ Recently, electrochemical cells for ITIES studies were adapted for the interfacing spectroscopy methods such as Raman spectroscopy, ${ }^{99-101}$ X-Ray absorption spectroscopy ${ }^{102}$ and spatial scanning spectroscopy. ${ }^{103}$ Girault's group has harnessed electrochemistry at the ITIES with electrospray ionisation mass spectrometry. ${ }^{104,105} \mathrm{~A}$ number of experimental arrangements was devised to follow interfacial electrochemical processes by mass spectrometry. Hence, a biphasic electrospray ionisation combined with the ITIES allowed the elucidation of the interactions between lysozyme and organic electrolyte anions as they are described in Figure 3A. ${ }^{104}$ Although electrospray ionisation is a powerful technique for the mass spectrometry study of proteins, it suffers from the occurrence of electrochemical reactions at the electrospray electrode. This drawback was circumvented by the introduction of the electrostatic spray ionisation (ESTASI) method, in which the electrospray electrode is separated from the sample by an insulating substrate. This method was then used for fingerprinting the tertiary structure of lysozyme, previously adsorbed by electrochemistry at the ITIES on a gel phase (Figure 5) ${ }^{105}$ It consisted of three steps: (i) the electroadsorption of proteins at the gel; (ii) the transfer of the gel onto the ESTASI substrate and (iii) the running of the ESTASI-MS experiments. The mass spectra confirmed the hypothesis based on electrochemical results, ${ }^{55}$ that multiple layers of proteins were adsorbed at the ITIES during the preconcentration step of adsorptive stripping voltammetry.

Modification of the liquid-liquid interface. Although the lack of sensitivity of electrochemistry at the ITIES has been overcome, the issue of selectivity remains. lonophores, used for the elaboration of ion-selective electrodes, have been extensively used at the ITIES. Unfortunately, they do not solve all the issues related to selectivity. The modification of the liquid-liquid interface may contribute further to improve the selectivity, analogously to the modification of solid electrodes. Among the various strategies to modify an electrode surface, silica mesoporous has appeared over the years as a simple 
and efficient way of introducing selectivity and functionality to an electrode. ${ }^{106}$ In a similar fashion, mesoporous silica materials have been deposited at the liquid-liquid interface by the means of evaporation ${ }^{107,108}$ or electrochemistry. ${ }^{109-111}$ Mesoporous silica is generated at the liquid-liquid interface by ion transfer of voltammetry of a surfactant, cetyltrimethylammonium, which is transferred from an organic phase to an aqueous phase containing hydrolysed silica precursor. The presence of surfactant in the aqueous phase catalyses the condensation of silica. ${ }^{109,110}$ Ion transfer voltammetry of six model ions (3 different tetraalkylammonium ions, 4-octylbenzenesulfonate, and two poly dendrimers) was used to characterise the electrodeposited mesoporous silica. Experiments have shown that the transfer of these ions differs depending on their size and charge. ${ }^{111}$ Chen and co-workers have used micro-interfaces modified with mesoporous silica for the detection of folic acid by differential pulse stripping voltammetry. ${ }^{108}$ Similarly, the behaviour of nanoparticles at the liquidliquid interface has been investigated for potential applications in the field of sensors or catalysis. ${ }^{112}$ Although the liquid-liquid interface was not polarised in most cases, there has been a substantial number of studies at the ITIES on the in-situ electrodeposition of metallic nanoparticles ${ }^{113}$ or on their self-assembly at the ITIES after ex-situ synthesis. ${ }^{114}$ These studies are essentially fundamental but they may pave the way for new (spectro)electrochemical sensing methods at the ITIES. These recent efforts for the modification of the interface have confirmed the need to investigate interfacial processes in-situ. A range of spectroscopic techniques was coupled to electrochemistry at the ITIES to monitor interfacial reactions such as metallic nanoparticles nucleation ${ }^{102,103}$ and adsorption ${ }^{99}$ and silica condensation. ${ }^{100}$

\section{Conclusions}

The frontier in ion sensing at the ITIES is constantly pushed forward as new target analytes are being detected, new methods are being developed and more and more analytical techniques are coupled to the electrochemistry at the ITIES. The possibility of detecting ions in real samples as complex as whole blood or environmental matrices also testifies of potential applications and eventually commercial products. The increasing interest for electrochemistry at the ITIES as an analytical technique over the years and the continued research efforts in interface modification with nanoobjects (nanoparticles, mesoporous silica or graphene) and in the coupling with other analytical techniques will contribute to the dynamism of the field over the next few years.

\section{Acknowledgments}

$\mathrm{GH}$ is grateful to the Agence Nationale pour la Recherche for the funding of the HYPERION project (grant number: ANR-14-CE14-0002-01).

\section{Biographical sketch}


Grégoire Herzog received his PhD in Chemistry from University College Cork (Ireland) in 2004. He then moved to Grenoble for a post-doc. In 2005, he joined the Tyndall National Institute in Cork, where he worked on the development of miniaturised electroanalytical tools based on ion transfer voltammetry at the liquid-liquid interface. Since 2011 , he is a researcher at the Laboratoire de Chimie Physique et Microbiologie pour l'Environnement (CNRS-Université de Lorraine, Nancy, France) where he is working on the electrochemical modification of the liquid-liquid interface with mesoporous silica films.

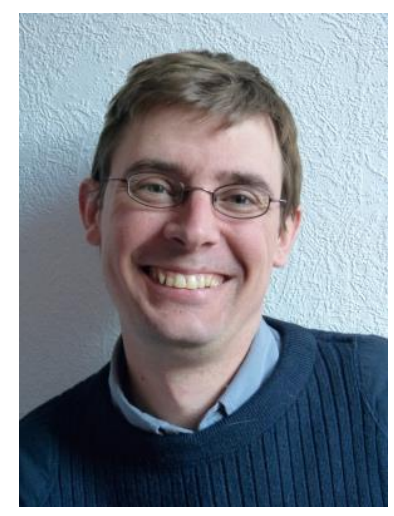

\section{References}

1. W. Nernst and E. H. Riesenfeld, Ann. Phys., 1902, 8, 600-608.

2. J. Wang, Analytical Electrochemistry, John Wiley and Sons, Hoboken, New Jersey, 3rd edn., 2006.

3. D. W. Kimmel, G. Leblanc, M. E. Meschievitz, and D. E. Cliffel, Anal. Chem., 2012, 84, 685-707.

4. A. J. Olaya, P. Ge, and H. H. Girault, Electrochem. Commun., 2012, 19, 101-104.

5. P. S. Toth and R. A. W. Dryfe, Analyst, 2015, 140, 1947-1954.

6. N. E. A. Cousens and A. R. Kucernak, Electrochem. Commun., 2011, 13, 1539-1541.

7. T. Kakiuchi, Anal. Chem., 2007, 79, 6442-6449.

8. A. J. Bard and L. R. Faulkner, Eletrochemical Methods: Fundamentals and Applications, John Wiley and Sons, New York, 2nd Ed., 2001.

9. K. B. Oldham, J. C. Myland, and A. M. Bond, Electrochemical Science and Technology: Fundamentals and Applications, Wiley, Chichester, 2012.

10. Z. Samec, Chem. Rev., 1988, 88, 617-632.

11. B. Liu and M. V. Mirkin, Electroanalysis, 2000, 12, 1433-1446.

12. Z. Samec, Pure Appl. Chem., 2004, 76, 2147-2180.

13. R. A. W. Dryfe, Phys. Chem. Chem. Phys., 2006, 8, 1869-1883. 
14. D. W. M. Arrigan, Anal. Lett., 2008, 41, 3233-3252.

15. R. A. W. Dryfe, in Advances in Chemical Physics, ed. S. A. Rice, John Wiley and Sons, 2009 , vol. 141, pp. 153-215.

16. H. H. Girault, in Electroanalytical Chemistry, Vol. 23, eds. A. J. Bard and C. G. Zoski, CRC Press, Boca Raton, 2010, pp. 1-104.

17. M. A. Méndez, R. Partovi-Nia, I. Hatay, B. Su, P. Ge, A. Olaya, N. Younan, M. Hojeij, and H. H. Girault, Phys. Chem. Chem. Phys., 2010, 12, 15163-15171.

18. S. Liu, Q. Li, and Y. Shao, Chem. Soc. Rev., 2011, 40, 2236-53.

19. Z. Samec, Electrochim. Acta, 2012, 84, 21-28.

20. D. W. M. Arrigan, G. Herzog, M. D. Scanlon, and J. Strutwolf, in Electroanalytical Chemistry, Vol. 25, eds. A. J. Bard and C. G. Zoski, CRC Press, Boca Raton, 2013, pp. 105-178.

21. S. Amemiya, J. Kim, A. Izadyar, B. Kabagambe, M. Shen, and R. Ishimatsu, Electrochim. Acta, 2013, 110, 836-845.

22. G. Herzog and V. Beni, Anal. Chim. Acta, 2013, 769, 10-21.

23. G. A. Crespo and E. Bakker, RSC Adv., 2013, 3, 25461-25474.

24. E. Bakker, TrAC - Trends Anal. Chem., 2014, 53, 98-105.

25. H. Tian, Y. Li, H. Shao, and H. Z. Yu, Anal. Chim. Acta, 2014, 855, 1-12.

26. T. Osakai, Y. Yuguchi, E. Gohara, and H. Katano, Langmuir, 2010, 26, 11530-11537.

27. G. Herzog, S. Flynn, C. Johnson, and D. W. M. Arrigan, Anal. Chem., 2012, 84, 5693-5699.

28. R. Matsui, T. Sakaki, and T. Osakai, Electroanalysis, 2012, 24, 2325-2331.

29. G. A. Crespo, M. G. Afshar, D. Dorokhin, and E. Bakker, Anal. Chem., 2014, 86, 1357-1360.

30. R. Matsui, T. Sakaki, and T. Osakai, Electroanalysis, 2012, 24, 1164-1169.

31. E. Grygolowicz-Pawlak and E. Bakker, Anal. Chem., 2010, 82, 4537-4542.

32. E. Grygolowicz-Pawlak and E. Bakker, Electrochem. Commun., 2010, 12, 1195-1198.

33. E. Grygolowicz-Pawlak, A. Numnuam, P. Thavarungkul, P. Kanatharana, and E. Bakker, Anal. Chem., 2012, 84, 1327-1335.

34. A. Shvarev, B. Neel, and E. Bakker, Anal. Chem., 2012, 84, 8038-8044.

35. M. Sohail, R. De Marco, K. Lamb, and E. Bakker, Anal. Chim. Acta, 2012, 744, 39-44.

36. J. Zhang, A. R. Harris, R. W. Cattrall, and A. M. Bond, Anal. Chem., 2010, 82, 1624-1633.

37. R. Ishimatsu, A. Izadyar, B. Kabagambe, Y. Kim, J. Kim, and S. Amemiya, J. Am. Chem. Soc., 2011, 133, 16300-16308. 
38. R. Mirshafian, P. Norouzi, and M. R. Ganjali, Electroanalysis, 2012, 24, 433-438.

39. B. Kabagambe, A. Izadyar, and S. Amemiya, Anal. Chem., 2012, 84, 7979-7986.

40. A. R. Harris, J. Zhang, R. W. Cattrall, and A. M. Bond, Anal. Methods, 2013, 5, 3840-3852.

41. B. Kabagambe, M. B. Garada, R. Ishimatsu, and S. Amemiya, Anal. Chem., 2014, 86, 79397946.

42. M. B. Garada, B. Kabagambe, Y. Kim, and S. Amemiya, Anal. Chem., 2014, 86, 11230-11237.

43. P. Lopes and R. Kataky, Anal. Chem., 2012, 84, 2299-2304.

44. M. M. Hossain, C. S. Kim, H. J. Cha, and H. J. Lee, Electroanalysis, 2011, 23, 2049-2056.

45. M. M. Hossain, S. N. Faisal, C. S. Kim, H. J. Cha, S. C. Nam, and H. J. Lee, Electrochem. Commun., 2011, 13, 611-614.

46. A. Benvidi, S. N. Lanjwani, and Z. Ding, Electrochim. Acta, 2010, 55, 2196-2200.

47. S. N. Faisal, C. M. Pereira, S. Rho, and H. J. Lee, Phys. Chem. Chem. Phys., 2010, 12, 1518415189.

48. T. J. Stockmann, Y. Lu, J. Zhang, H. H. Girault, and Z. Ding, Chem. - A Eur. J., 2011, 17, 1320613216.

49. T. J. Stockmann, A. M. Montgomery, and Z. Ding, Anal. Chem., 2012, 84, 6143-6149.

50. T. J. Stockmann, J. Zhang, A. M. Montgomery, and Z. Ding, Anal. Chim. Acta, 2014, 821, 41-47.

51. Y. Qiao, B. Zhang, X. Zhu, T. Ji, B. Li, Q. Li, E. Chen, and Y. Shao, Electroanalysis, 2013, 25, 1080-1084.

52. J. A. Ribeiro, I. M. Miranda, F. Silva, and C. M. Pereira, Phys. Chem. Chem. Phys., 2010, 12, 15190-15194.

53. J. A. Ribeiro, F. Silva, and C. M. Pereira, Electroanalysis, 2013, 25, 2331-2338.

54. G. Herzog, A. Roger, D. Sheehan, and D. W. M. Arrigan, Anal. Chem., 2010, 82, 258-264.

55. E. Alvarez De Eulate and D. W. M. Arrigan, Anal. Chem., 2012, 84, 2505-2511.

56. S. O'Sullivan and D. W. M. Arrigan, Electrochim. Acta, 2012, 77, 71-76.

57. E. Alvarez de Eulate, S. O'Sullivan, S. Fletcher, P. Newsholme, and D. W. M. Arrigan, Chem. Asian J., 2013, 8, 2096-2101.

58. S. O'Sullivan, E. Alvarez de Eulate, Y. H. Yuen, E. Helmerhorst, and D. W. M. Arrigan, Analyst, 2013, 138, 6192-6196.

59. E. Alvarez De Eulate, L. Serls, and D. W. M. Arrigan, Anal. Bioanal. Chem., 2013, 405, 38013806.

60. S. O'Sullivan and D. W. M. Arrigan, Anal. Chem., 2013, 85, 1389-1394. 
61. C. J. Collins, C. Lyons, J. Strutwolf, and D. W. M. Arrigan, Talanta, 2010, 80, 1993-1998.

62. J. A. Ribeiro, F. Silva, and C. M. Pereira, Anal. Chem., 2013, 85, 1582-1590.

63. P. Vazquez, G. Herzog, C. O’Mahony, J. O’Brien, J. Scully, A. Blake, C. O’Mathuna, and P. Galvin, Sensor. Actuat. B, 2014, 201, 572-578.

64. M. Sairi and D. W. M. Arrigan, Talanta, 2015, 132, 205-214.

65. J. A. Ribeiro, F. Silva, and C. M. Pereira, Talanta, 2012, 88, 54-60.

66. A. Mastouri, S. Peulon, D. Farcage, N. Bellakhal, and A. Chaussé, Electrochim. Acta, 2014, 120, 212-218.

67. M. M. Hossain, S. H. Lee, H. H. Girault, V. Devaud, and H. J. Lee, Electrochim. Acta, 2012, 82, 12-18.

68. S. H. Lee, H. Kim, H. H. Girault, and H. J. Lee, Bull. Korean Chem. Soc., 2013, 34, 2577-2582.

69. M. Hossain, H. H. Girault, and H. J. Lee, Bull. Korean Chem. Soc., 2012, 33, 1734-1740.

70. A. Mastouri, S. Peulon, N. Bellakhal, and A. Chaussé, Electrochim. Acta, 2014, 130, 818-825.

71. A. Molina, E. Laborda, and R. G. Compton, Chem. Phys. Lett., 2014, 597, 126-133.

72. A. Molina, E. Laborda, and R. G. Compton, J. Phys. Chem. C, 2014.

73. A. Molina, E. Laborda, J. González, and R. G. Compton, Electroanalysis, 2015, 27, $93-100$.

74. J. S. Ellis, J. Strutwolf, and D. W. M. Arrigan, Phys. Chem. Chem. Phys., 2012, 14, 2494-500.

75. P. Elsamadisi, Y. Wang, J. Velmurugan, and M. V Mirkin, Anal. Chem., 2011, 83, 671-673.

76. M. D. Scanlon, J. Strutwolf, A. Blake, D. Iacopino, A. J. Quinn, and D. W. M. Arrigan, Anal. Chem., 2010, 82, 6115-6123.

77. M. Sairi, N. Chen-Tan, G. Neusser, C. Kranz, and D. W. M. Arrigan, ChemElectroChem, 2015, 2, 98-105.

78. M. Rimboud, R. D. Hart, T. Becker, and D. W. M. Arrigan, Analyst, 2011, 136, 4674-4681.

79. M. D. Scanlon and D. W. M. Arrigan, Electroanalysis, 2011, 23, 1023-1028.

80. M. Sairi, J. Strutwolf, R. A. Mitchell, D. S. Silvester, and D. W. M. Arrigan, Electrochim. Acta, 2013, 101, 177-185.

81. Y. Liu, J. Strutwolf, and D. W. M. Arrigan, Anal. Chem., 2015, 87, 4487-4494.

82. D. S. Silvester, Analyst, 2011, 136, 4871-4882.

83. T. Stockmann and Z. Ding, Anal. Chem., 2011, 83, 7542-7549.

84. J. Strutwolf, M. D. Scanlon, and D. W. M. Arrigan, J. Electroanal. Chem., 2010, 641, 7-13. 
85. J. Strutwolf and D. W. M. Arrigan, Anal. Bioanal. Chem., 2010, 398, 1625-1631.

86. E. Bakker, Anal. Chem., 2011, 83, 486-493.

87. M. L. Colombo, J. V. Sweedler, and M. Shen, Anal. Chem., 2015, doi:10.1021/ac504151e.

88. J. Langmaier, Z. Samec, E. Samcová, and P. Tůma, Electrochem. Commun., 2012, 24, 25-27.

89. H. R. Kim, C. M. Pereira, H. Y. Han, and H. J. Lee, Anal. Chem., 2015, in press.

90. C. J. Collins and D. W. M. Arrigan, Anal. Chem., 2009, 81, 2344-2349.

91. S. Amemiya, Y. Kim, R. Ishimatsu, and B. Kabagambe, Anal. Bioanal. Chem., 2011, 399, 571579.

92. D. W. M. Arrigan, Annu. Rep. Prog. Chem., Sect C Phys. Chem., 2013, 109, 167-188.

93. C. J. Collins and D. W. M. Arrigan, Anal. Bioanal. Chem., 2009, 393, 835-45.

94. Y. Yamini, S. Seidi, and M. Rezazadeh, Anal. Chim. Acta, 2013, 814, 1-22.

95. Z. Samec, A. Trojánek, J. Langmaier, and E. Samcova, J. Electroanal. Chem., 2000, 481, 1-6.

96. M. Velický, K. Y. Tam, and R. A. W. Dryfe, Anal. Chem., 2012, 84, 2541-2547.

97. M. Velický, K. Y. Tam, and R. A. W. Dryfe, Anal. Chem., 2014, 86, 435-442.

98. D. J. Fermin, in Diffraction and Spectroscopic Methods in Electrochemistry, eds. R. C. Alkire, D. M. Kolb, J. Lipkowski, and P. N. Ross, Wiley- VCH, Weinheim, 2006, pp. 127-162.

99. S. G. Booth, D. P. Cowcher, R. Goodacre, and R. A. W. Dryfe, Chem. Commun., 2014, 44824484.

100. L. Poltorak, M. Dossot, G. Herzog, and A. Walcarius, Phys. Chem. Chem. Phys., 2014, 16, 26955-26962.

101. D. Ibañez, D. Plana, A. Heras, D. J. Fermín, and A. Colina, Electrochem. Commun., 2015, 54, 1417.

102. Y. Gründer, J. F. W. Mosselmans, S. L. M. Schroeder, and R. A. W. Dryfe, J. Phys. Chem. C, 2013, 117, 5765-5773.

103. D. Izquierdo, A. Martinez, A. Heras, J. Lopez-Palacios, V. Ruiz, R. A. W. Dryfe, and A. Colina, Anal. Chem., 2012, 84, 5723-30.

104. R. A. Hartvig, M. A. Méndez, M. van de Weert, L. Jorgensen, J. Østergaard, H. H. Girault, and H. Jensen, Anal. Chem., 2010, 82, 7699-7705.

105. E. Alvarez de Eulate, L. Qiao, M. D. Scanlon, H. H. Girault, and D. W. M. Arrigan, Chem. Commun., 2014, 50, 11829-32.

106. A. Walcarius, Chem. Soc. Rev., 2013, 42, 4098-4140.

107. S. Bian, K. Gao, H. Shen, X. Jiang, Y. Long, and Y. Chen, J. Mater. Chem. B, 2013, 1, 3267-3276. 
108. X. Jiang, K. Gao, D. Hu, H. Wang, S. Bian, and Y. Chen, Analyst, 2015, doi:10.1039/C4AN02011A.

109. L. Poltorak, G. Herzog, and A. Walcarius, Electrochem. Commun., 2013, 37, 76-79.

110. L. Poltorak, G. Herzog, and A. Walcarius, Langmuir, 2014, 30, 11453-11463.

111. L. Poltorak, K. Morakchi, G. Herzog, and A. Walcarius, Electrochim. Acta, 2015, 10.1016/j.electacta.2015.01.129.

112. J. B. Edel, A. A. Kornyshev, and M. Urbakh, ACS Nano, 2013, 7, 9526-9532.

113. A. N. J. Rodgers, S. G. Booth, and R. A. W. Dryfe, Electrochem. Commun., 2014, 47, 17-20.

114. P. P. Fang, S. Chen, H. Deng, M. D. Scanlon, F. Gumy, H. J. Lee, D. Momotenko, V. Amstutz, F. Cortés-Salazar, C. M. Pereira, Z. Yang, and H. H. Girault, ACS Nano, 2013, 7, 9241-9248. 


\section{Figure Captions}

Figure 1: Most common experimental set-ups for electrochemistry at the ITIES: (A) classical macroscopic ITIES, (B) membrane-supported ITIES, (C) thin organic film, (D) single $\mu$ ITIES and (E) $\mu$ ITIES array. The aqueous phase is represented in blue and the organic phase in orange. $\mathrm{RE}_{\text {org: }}$ : reference electrode for the organic phase, $\mathrm{RE}_{\mathrm{aq}}$ : reference electrode for the aqueous phase, $\mathrm{CE}_{\mathrm{org}}$ : counter electrode for the organic phase, $\mathrm{CE}_{\mathrm{aq}}$ : counter electrode for the aqueous phase, $\mathrm{M}$ : Membrane; $X^{Z_{i}}$ : ionic species of charge $Z_{i}$ in the aqueous phase $(w)$ or in the organic phase (o); $A_{\text {red: }}$ : reduced form of an electroactive species; $A_{o x}$ : oxidised form of an electroactive species.

Figure 2: (A) Schematic representation of the thin layer coulometric cell used for (B) the indirect determination of heparin concentration in undiluted blood samples. Adapted with permission from Ref. ${ }^{29}$ Copyright 2014 American Chemical Society.

Figure 3: Origin of the analytical signal for protein detection at the ITIES in (A) the absence and (B) the presence of surfactants in the organic phase. The arrows indicate which ionic species are transferring. Cyclic voltammograms for haemoglobin ( $\mathrm{Hb})$, cytochrome $\mathrm{c}(\mathrm{Cyt} \mathrm{c}$ ) and myoglobin (Mb) in (C) the absence and (D) the presence of surfactant in the organic phase. Adapted with permission from Ref. ${ }^{60}$ Copyright 2013 American Chemical Society.

Figure 4: (A) Schematic representation of the supported liquid membrane, M, separating two aqueous phases $A$ and $B . R_{A}$ ad $R E_{B}$ are the reference electrodes and $C E_{A}$ and $C E_{B}$ are the counter electrodes. (B) Cyclic voltammograms for tetramethylammonium $\left(\mathrm{TMA}^{+}\right)$, tetraethylammonium $\left(\mathrm{TEA}^{+}\right)$tetrabutylammonium $\left(\mathrm{TBA}^{+}\right)$and Crystal Violet $\left(\mathrm{CrV}^{+}\right)$. Adapted with permission from Ref. ${ }^{97}$ Copyright 2014 American Chemical Society.

Figure 5: (A) Experimental procedure for the electrostatic spray ionisation mass spectrometry involving (1) electrochemical preconcentration, (2) gel removal and (3) mass spectrometry analysis. (B) Mass spectrum obtained for the electroadsorption of $10 \mu \mathrm{M}$ lysozyme for $30 \mathrm{~min}$ at an interfacial potential of $1.0 \mathrm{~V}$. Adapted from Ref. ${ }^{105}$ 
Figure 1

A Classical macrolTIES

B Membranesupported ITIES

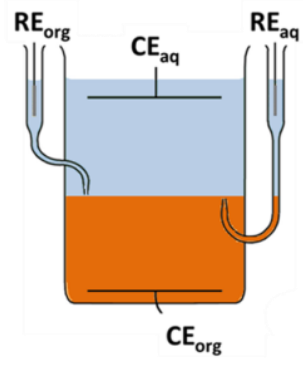

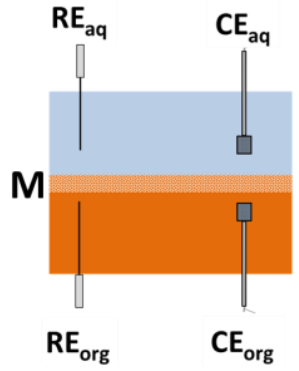

C Thin organic film

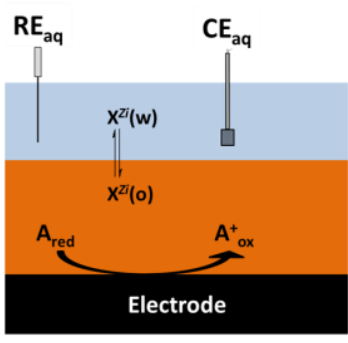

D Single $\mu$ ITIES

$\mathrm{RE}_{\text {aq }} \mathrm{CE} / \mathrm{RE}_{\text {org }} \quad \mathrm{CE}_{\text {aq }}$
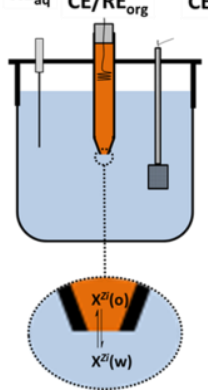

E $\mu$ ITIES array

$\mathrm{RE}_{\text {aq }} \mathrm{CE} / \mathrm{RE}_{\text {org }} \quad \mathrm{CE}_{\text {aq }}$

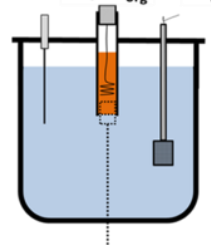

$\prod_{x^{z}(w)}^{x^{z}(0)}$ 
Figure 2
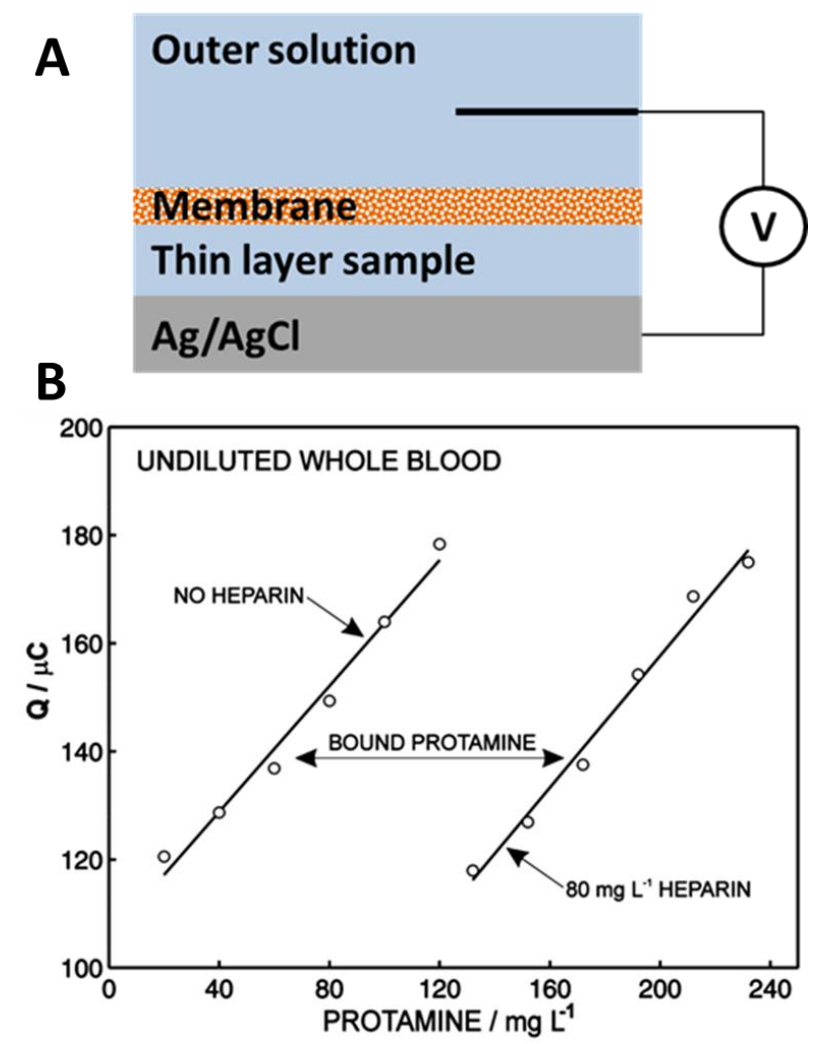
Figure 3

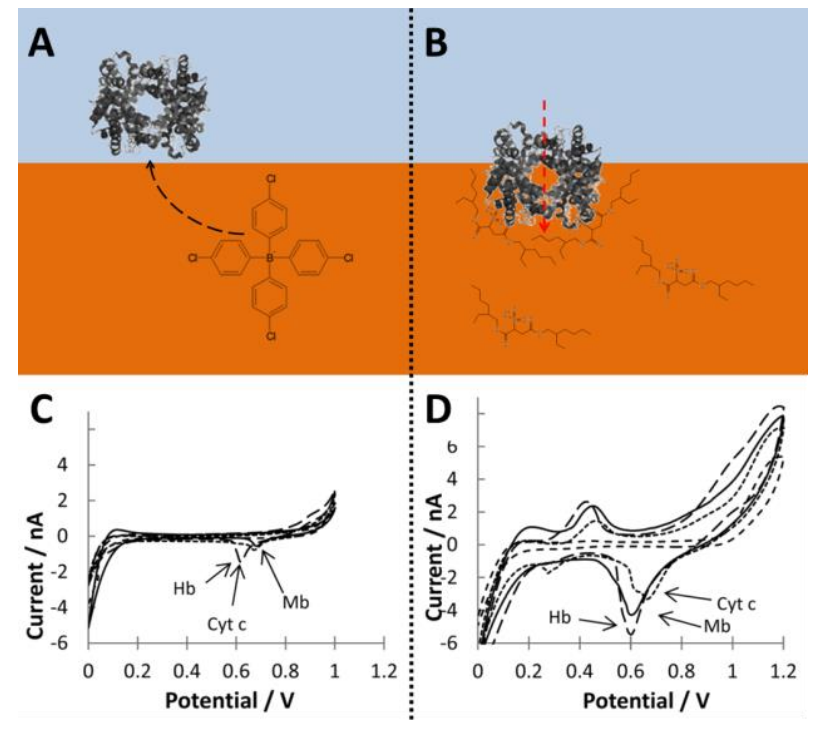


Figure 4

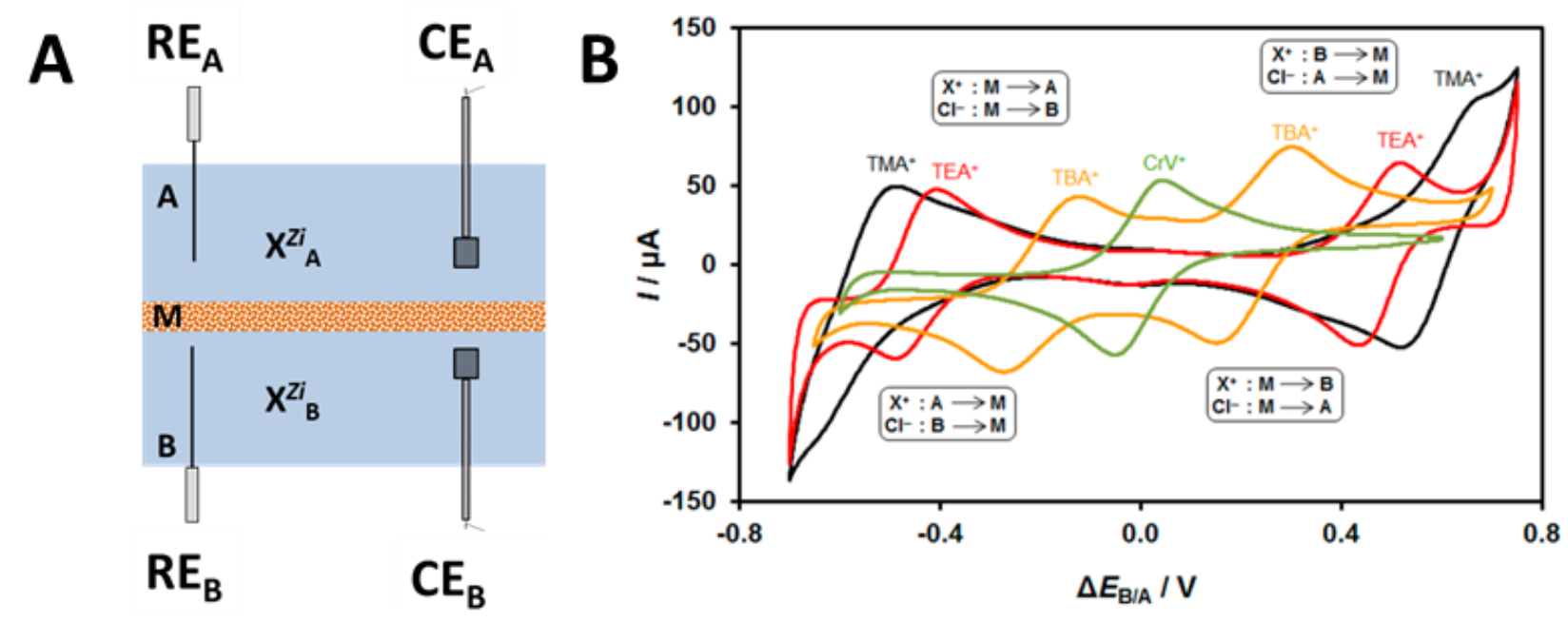


Figure 5

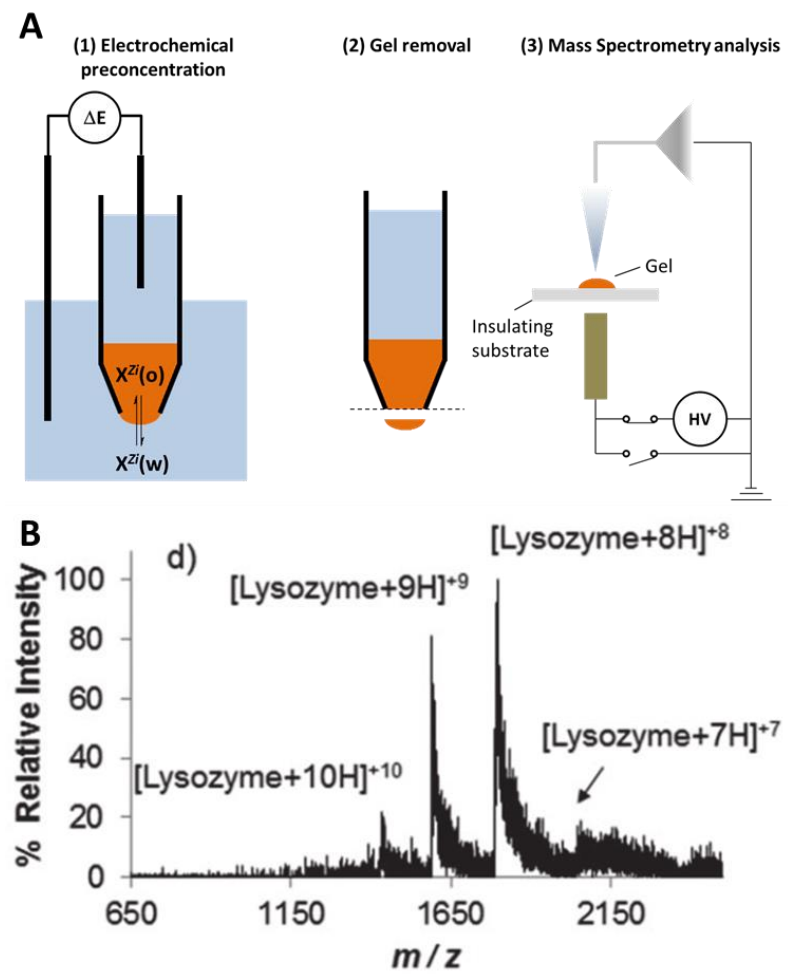


